\title{
Application of the Technology Acceptance Model to an Intelligent Cost Estimation System: An Empirical Study in the Automotive Industry
}

\author{
Frank Bodendorf \\ Friedrich-Alexander-University of Erlangen- \\ Nuremberg (FAU) \\ frank.bodendorf@faps.fau.de
}

\author{
Jörg Franke \\ Friedrich-Alexander-University of Erlangen- \\ Nuremberg (FAU) \\ Joerg.franke@faps.fau.de
}

\begin{abstract}
Cost estimation methods are crucial to support inter- and intraorganizational cost management. Despite intense research on machine learning and deep learning for the prediction of costs, the acceptance of such models in practice remains unclear. The aim of this study is to evaluate the acceptance of an implemented deep learning-based cost estimation system. In an empirical study at a large Bavarian automotive manufacturer we use surveys to collect opinions and concerns from experts who regularly use the system. The evaluation is framed by the basic theories of the Technology Acceptance Model. The results from 50 questionnaires and qualitative participant observations show further development potentials of intelligent cost estimation systems in terms of perceived usefulness and userfriendliness. Building on our empirical findings we provide implications for both research and practice.
\end{abstract}

\section{Introduction}

Optimizing cost continues to be one of the focal points in purchasing and supply management [1]. Cost estimation is therefore widely adopted in new product development processes, in quotation calculation, in profitability analyses, as a criterion to define product prices, and for bidding purposes as well as supplier selection. In such applications, quantitative prediction techniques are increasingly used and supersede qualitative expert judgement. Quantitative methods include statistical parametric and machine learning methods [2]. In business practice parametric shouldcosting approaches based on activity based costing and statistical regression "proves its worth by helping companies reduce what their supplies actually cost" [3][4]. In addition to statistical regression H.S. Wang proposes machine learning as an advanced cost estimation method [5]. Machine learning and deep learning approaches can provide accurate and flexible estimation models with less data required. Just to give some examples, researchers have tried to use support vector machines [6][7] or neural network architectures [8][9][10][11] to solve cost regression problems. The authors demonstrate that these intelligent cost estimation methods, especially deep learning techniques, show high accuracies in various contexts. However, none of these research streams address the acceptance of such methods in real business practice. Often these machine learning techniques are black boxes and do not allow managers and stakeholders to gain insights into the decision making process, which in turn makes them difficult to apply in practice and leads practitioners to resort to old manual methods.

Furthermore, previous research on the acceptance of intelligent systems seems to be outdated as new concepts like explainable artificial intelligence or the consideration of causalities lead to a higher acceptance of machine and deep learning methods in general [12] and for cost estimation in particular due to the increased transparency for decision makers.

Thus, this paper aims to investigate the acceptance of an intelligent and more transparent deep learning system for cost estimation.

This paper introduces an empirical study at a large Bavarian automotive manufacturer to investigate the use and acceptance of deep learning-based cost estimation, following the common technology acceptance model (TAM).

Section 2 of this paper takes a short look at the theoretical background of TAM. Section 3 outlines the conceptual framework and derived hypotheses of this study. Section 4 gives insights into the statistical analysis and results of the TAM-based study. Section 5 shows implications for research and practice. Finally, Section 6 concludes this paper by a concise summary.

\section{Background}

\subsection{Deep Learning for Cost Estimation}

Deep learning-based information processing models can consist of numerous layers and elementary 
computational units (neurons) connected by weighted links [13]. Deep learning often refers to artificial neural networks (ANN) which learn from a set of training data (in this research, cost drivers and total costs) and assist decision makers in their management task. Moreover, ANN can be considered as "universal regression tools" [14] capable of approximating any continuous function, which justifies their use in cost estimation applications in practice. In particular, ANNs are nonparametric estimators [15], which means that no assumptions about the shape of the approximation function need to be made before training. This is a great practical advantage because it saves time and effort for a cost engineering expert needed, to find the appropriate function type in parametric costing. As a basis for the empirical investigation a multilayer perceptron network (see Figure 1) is implemented because this configuration provides the best results as a function approximator [16][17]. This has also been confirmed in numerous case studies in literature. For a deeper insight into related work in the field of cost estimation using deep learning, we refer to the literature review by Bodendorf et al. [18] .

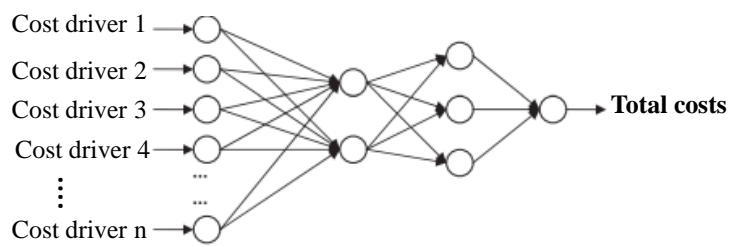

\section{Figure 1. Scheme of the adopted ANN}

In order to increase the lack of transparency of deep learning, procedures of post hoc explainability like local explanations and feature relevance techniques are implemented. For a deeper discussion on those techniques we refer to Arrieta et al. [12].

\subsection{Technology Acceptance Model (TAM)}

The acceptance of technologies is important for their integration in the company. According to [19], the effectiveness of decision support systems inspired by artificial intelligence (AI) is particularly influenced by the acceptance and use of practitioners. Therefore, in the context of this paper, the TAM developed by [20] is used to investigate and explain the acceptance of a developed cost estimation model based on machine learning. The conceptualization of this model allows for a general explanation approach guided by theory. With this approach, the acceptance or nonacceptance of learning-based intelligent system applications from the end user's point of view is compensated for a small number of behaviorally relevant influencing factors and presented in a simple as well as a descriptive form. In addition, the TAM enables a methodologically sound evaluation [21].

According to TAM, perceived ease of use and perceived usefulness have a great influence on the acceptance of the use of certain systems or technologies. This can be explained as individuals are more likely to consider a technology if they perceive the technology to be useful and easy to use. In the organizational context F.D. Davis [20] defines perceived ease of use (PEoU) as "the degree to which a person believes that using a particular system would be free of effort." Perceived usefulness (PU) is defined as "the degree to which a person believes that using a particular system would enhance his or her job performance" [20]. The interrelationship between these two constructs is shown in Figure 2.

This basic theory has been confirmed by a lot of studies and extended, for example, to TAM2 [22], TAM3 [23], or UTAUT [24] by including more influencing factors. E. g., various external factors are assumed and analyzed for their influence on acceptance by [20]. TAM has been used in different fields for explaining the intention to use such as for internet-based intelligent systems [25], intelligent robots based on AI [26], intelligent learning systems [27][28][29], for electric mobility [30], for information and communication technologies [31] or generally for diverse AI applications [32].

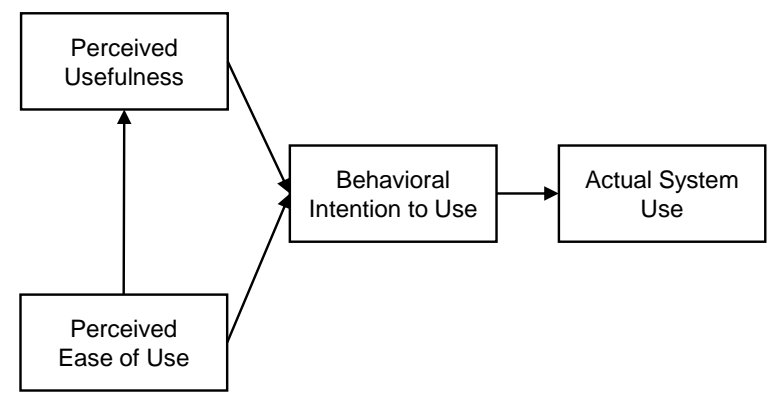

Figure 2. TAM according to [20]

\section{Conceptual Framework and Hypotheses}

The basic TAM according to [20] is usually extended by additional factors. Furthermore, it is confirmed that there is a direct relationship between PEoU and PU, as increased usability can be associated with greater ease of use of a system [33]. In this paper, the basic constructs of acceptance are examined in detail in this regard, since in the context of [19] and [20] the perceived ease of use and usefulness are important in the context of an intelligent cost 
estimation model. Following the basic model, hypotheses $\mathrm{H} 1, \mathrm{H} 2$, and $\mathrm{H} 3$ are formulated:

H1: The PU has a positive impact on the behavioral intention to use (BI) of the intelligent cost estimation system.

$\mathrm{H} 2$ : The PEoU has a positive influence on the BI of the intelligent cost estimation system.

$\mathrm{H} 3$ : The PEoU has a positive influence on the PU of the intelligent cost estimation system.

The research paper by [20] extends the TAM by looking at usage intention and perceived usefulness in more detail. For this purpose, both socially influential constructs and cognitive instrumental constructs are added. Within the socially influencing constructs the subjective norm ( $\mathrm{SN}$ ), the image (IM) as well as the experience and the voluntariness of use are analyzed. Furthermore, the TAM is extended by the constructs of job relevance (JR), result demonstrability (RD) and output quality (OQ), which can be assigned to the cognitive instrumental constructs. This theoretical model is confirmed by the work of [22], using four different information system architectures within four different companies. In the context of technologies based on AI, [34] comprehensively examines, among other things, AI applications as well as the acceptance of AI in practice. In [35], regarding AI applications for decision support in the context of big data, wideranging research approaches are identified that also target user behavior and interaction with the system as well as personal value views and the design of the AI system. In this regard, the analysis in [36] of the readiness for AI applications is also relevant. Based on these publications, influencing constructs regarding
SN, IM, JR, RD as well as OQ can be derived for the intelligent cost estimation system investigated in this paper. This results in the following hypotheses $\mathrm{H} 4$ to H15. Their interrelationship is shown in the enhanced analysis model in Figure 3.

$\mathrm{H} 4$ : $\mathrm{SN}$ has a positive influence on BI of the intelligent cost estimation system.

H5: SN has a positive influence on PU of the intelligent cost estimation system.

H6: SN has a positive influence on PEoU of the intelligent cost estimation system.

H7: SN has a positive influence on IM of the intelligent cost estimation system.

H8: IM has a positive influence on PU of the intelligent cost estimation system.

H9: IM has a positive influence on PEoU of the intelligent cost estimation system.

H10: JR has a positive influence on PU of the intelligent cost estimation system.

H11: JR has a positive influence on PEoU of the intelligent cost estimation system.

H12: OQ has a positive influence on PU of the intelligent cost estimation system.

H13: OQ has a positive influence on PEoU of the intelligent cost estimation system.

H14: RD has a positive influence on PU of the intelligent cost estimation system.

H15: RD has a positive influence on PEoU of the intelligent cost estimation system.

These research hypotheses and the resulting TAM in Figure 3 are analyzed and evaluated empirically at the automotive manufacturer.

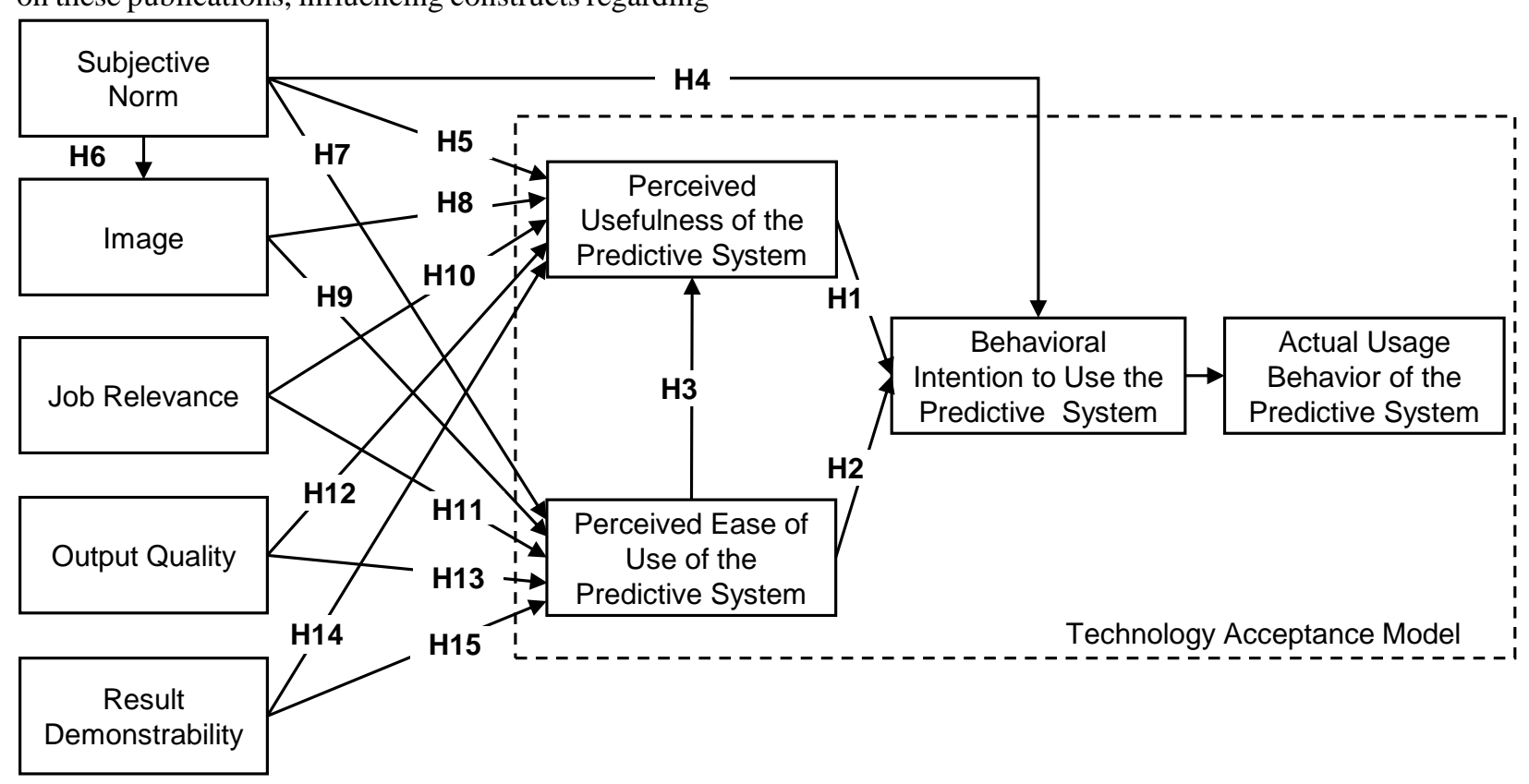

Figure 3. Representation of the TAM for the intelligent cost estimation method 


\section{Empirical Study}

\subsection{Preprocessing and Sample Characteristics}

For assessing the acceptance of using the developed cost estimation model, an online survey is conducted with 50 employees (cost, financial controlling, purchasing, and supply chain managers). Additionally, participant observations are carried out and documented to get deeper insights into real-time applications of the deep learning-based cost estimation system. All participants at the automotive manufacturer have already tested the intelligent cost estimation model in practice. The number of participants interviewed is based on the TAM field studies conducted in the foundational work of [22]. The questionnaire is created following the basic constructs and scales from [20] and [22]. It includes 23 items to be answered with a 7-point scale. Such a Likert scale is often used in the context of the TAM as in [31], [22] or [24]. Here, a score of one implies that respondents disagree with the statement at all and a score of seven implies that respondents completely agree with the statement.

\subsection{Results}

In this paper, a structural equation model (SEM) is used for the analysis of the hypotheses to investigate the acceptance of the technology. Explicitly, the component-oriented and prediction-oriented SEM, which is called partial least square (PLS), is used to consider the effects between constructs [31] [37] [38]. In general, the SEM is frequently used for analyses based on the TAM, as can also be seen in the previously mentioned applications and represents an established model for the analysis of behavioral data in the field of computer science [39]. For the entire analysis in this paper, the software SmartPLS 3 is used due to simplified usability and availability of all necessary functions [40].

For quality assessment the constructs of the model presented in Figure 2 are first checked for reliability and validity. For this purpose, the normality of the data distribution is first analyzed by the so-called measurement model using the values for kurtosis and skewness. If the data has a univariate normal distribution, values between -1.5 and 1.5 can be assumed for both kurtosis and skewness [41]. The definitions of considered TAM items are outlined in Table 1 and the results are presented in Table 2 . It can be seen that all values of the constructs for the cost estimation system are within the expected value range for a univariate normal distribution of the data. Thus, a normal distribution of the values can be confirmed. To check whether all respondents have a similar interpretation of the questions, the internal consistency and reliability of the factors within the questionnaire are analyzed using Cronbach's Alpha (CA). Here, a value $\mathrm{CA}>0.7$ provides evidence of acceptable reliability. Furthermore, the analysis of convergent validity implies a high correlation of the items of a single construct. Here, it is assumed that if the consistent factor loading is greater than 0.7 , if the average variance extracted (AVE) is greater than 0.5 of each construct, and if the reliability of each construct is greater than 0.7 , there is evidence of convergent validity [39][40].

Table 1. TAM item definition according to [22] Item Definition

PU1 Using the intelligent cost estimation system would improve my daily work performance.

PU2 Using the intelligent cost estimating system would make my daily work easier.

PU3 Using the intelligent cost estimating system would increase the effectiveness of my daily work.

PU4 I would find the intelligent cost estimating system useful in my daily work tasks.

PEoU1 Using the intelligent cost estimation system is simple.

PEoU2 Interaction with the intelligent cost estimation system is clear and understandable.

PEoU3 Interacting with the system does not require much thinking.

PEoU4 I find it easy to use the intelligent cost estimating system so that it correctly executes my specifications to accomplish tasks.

BI1 Assuming I gain access to use the intelligent cost estimating system, I intend to use the system in my daily work.

BI2 Assuming availability of the intelligent cost estimating system, I would use the system regularly in my daily work.

SN1 People with an influence on my behavior will think that I should use the intelligent cost estimating system.

SN2 Important people in my life will think that I should use the intelligent cost estimating system. 
IM1 Colleagues who use the intelligent cost estimation system will have a higher standing in the company compared to those who do not use it.

IM2 Colleagues who use the intelligent cost estimating system will have a high standing in the company.

IM3 Using the intelligent cost estimation system implies a high standing in the company.

JR1 For my work tasks, the use of the intelligent cost estimating system would be important.

JR2 For my work tasks, the use of the intelligent cost estimation system would be relevant.

OQ1 The outputs of the intelligent cost estimation system are of high quality.

OQ2 I have no problem with the quality of the system output.

RD1 I would have no difficulty telling others about the results of using the intelligent cost estimating system.

RD2 I believe I could communicate to others the impact of using the system.

RD3 The results of using the intelligent cost estimating system are obvious to me.

RD4 I would have difficulty explaining why using the system may or may not be beneficial.

Table 2. Mean $(\mu)$, standard deviation $(\sigma)$, kurtosis, and skewness of TAM items

\begin{tabular}{lccrr}
\hline Item & $\boldsymbol{\mu}$ & $\boldsymbol{\sigma}$ & kurtosis & skewness \\
\hline PU1 & 5.040 & 0.631 & -0.419 & -0.032 \\
PU2 & 5.480 & 0.877 & -0.669 & -0.212 \\
PU3 & 5.580 & 0.802 & -0.302 & -0.270 \\
PU4 & 5.460 & 0.830 & -0.621 & -0.627 \\
PEoU1 & 4.040 & 1.148 & -0.463 & -0.408 \\
PEoU2 & 3.700 & 0.854 & -0.369 & -0.357 \\
PEoU3 & 3.140 & 0.959 & 0.136 & -0.571 \\
PEoU4 & 3.800 & 0.800 & 0.589 & -0.822 \\
BI1 & 4.380 & 0.797 & -0.483 & -0.080 \\
BI2 & 4.320 & 0.926 & 0.053 & -0.540 \\
SN1 & 5.240 & 0.838 & 0.159 & -0.910 \\
SN2 & 4.760 & 0.789 & 0.521 & -0.794 \\
IM1 & 4.680 & 0.882 & 0.747 & -0.753 \\
IM2 & 5.540 & 1.081 & 0.812 & -0.939 \\
IM3 & 4.700 & 0.877 & 0.895 & -0.824 \\
JR1 & 5.640 & 1.015 & -0.864 & -0.513 \\
JR2 & 5.880 & 1.125 & -0.884 & -0.712 \\
OQ1 & 5.520 & 0.640 & -0.009 & -1.021 \\
OQ2 & 5.560 & 0.668 & 0.368 & -1.264 \\
RD1 & 5.080 & 0.868 & 1.011 & -1.106
\end{tabular}

\begin{tabular}{lllrl} 
RD2 & 4.960 & 1.019 & -0.040 & -0.736 \\
RD3 & 4.800 & 0.894 & -0.678 & -0.277 \\
RD4 & 5.800 & 0.849 & 0.315 & -0.810 \\
\hline
\end{tabular}

Table 3 shows all values for the CA, the AVE, and the composite reliability value (CR) of each construct calculated using SmartPLS 3. Having a look at Table 2 it can be seen that the previously mentioned specifications are met. Thus, the model has convergent validity and acceptable reliability based on the fact that all CA values exceed 0.7 .

In addition, a discriminant analysis is performed to exclude a correlation between the items of different constructs. In this validity check of the model the correlation between the different constructs must be smaller than the square root of the AVE value. The results of this analysis using SmartPLS 3 can be found in Table 4. Here, the highlighted values on the diagonal represent all the AVE values of the square root, and all the underlying values of each column represent the correlations.

Table 3. CA, AVE and CR of the constructs of the TAM

\begin{tabular}{lrrr}
\hline Construct & CA & AVE & CR \\
\hline PU & 0.929 & 0.825 & 0.950 \\
PEoU & 0.956 & 0.883 & 0.968 \\
BI & 0.958 & 0.959 & 0.979 \\
SN & 0.897 & 0.906 & 0.951 \\
IM & 0.965 & 0.935 & 0.977 \\
JR & 0.942 & 0.945 & 0.972 \\
OQ & 0.839 & 0.861 & 0.925 \\
RD & 0.942 & 0.945 & 0.972 \\
\hline
\end{tabular}

Building on the results in Table 4, the validity of the discriminant can be confirmed, since all correlation values are lower than the marked AVE values of the square roots.

Table 4. Discriminant validity results of the TAM

\begin{tabular}{lrrrrrrrr}
\hline & IM & BI & JR & OQ & PEOU & PU & RD & SN \\
\hline IM & $\mathbf{0 . 9 6 7}$ & & & & & & & \\
BI & 0.839 & $\mathbf{0 . 9 8 0}$ & & & & & & \\
JR & 0.713 & 0.807 & $\mathbf{0 . 9 7 2}$ & & & & & \\
OQ & 0.763 & 0.822 & 0.807 & $\mathbf{0 . 9 2 8}$ & & & & \\
PEoU & 0.865 & 0.909 & 0.815 & 0.804 & $\mathbf{0 . 9 4 0}$ & & & \\
PU & 0.846 & 0.912 & 0.886 & 0.862 & 0.921 & $\mathbf{0 . 9 0 8}$ & & \\
RD & 0.781 & 0.812 & 0.757 & 0.778 & 0.853 & 0.861 & $\mathbf{0 . 9 0 1}$ & \\
SN & 0.675 & 0.756 & 0.729 & 0.765 & 0.728 & 0.812 & 0.711 & $\mathbf{0 . 9 5 2}$ \\
& & & & & & & & \\
\hline
\end{tabular}


According to [43], the number of subsamples should be large to obtain reasonable estimates. In this work, following the research of [31], the subsamples are set to 1000. In addition, 300 iterations of the PLSSEM algorithm are set in SmartPLS. Based on these settings, the structural model depicted in Figure 4 delivers the path coefficients, the outer factor loadings, and the values of $\mathrm{R}^{2}$ for the latent constructors. In this context, the results of the bootstrapping analysis are additionally presented in Table 5 .

Table 5. Results of the bootstrapping analysis of the TAM

\begin{tabular}{|c|c|c|c|c|c|}
\hline $\begin{array}{l}\text { Relation- } \\
\text { ship }\end{array}$ & $\begin{array}{r}\text { Path } \\
\text { coef- } \\
\text { ficient }\end{array}$ & $\mu$ & $\sigma$ & $\begin{array}{r}\text { T- } \\
\text { statistic }\end{array}$ & $\begin{array}{r}\text { p- } \\
\text { value }\end{array}$ \\
\hline $\mathbf{P U} \rightarrow \mathbf{B I}$ & $0.422 *$ & 0.437 & 0.177 & 2.389 & 0.017 \\
\hline PEoU $\rightarrow$ BI & $0.466 *$ & 0.434 & 0.138 & 3.389 & 0.001 \\
\hline PEoU $\rightarrow$ PU & 0.312 & 0.356 & 0.228 & 1.368 & 0.172 \\
\hline $\mathrm{SN} \rightarrow \mathrm{BI}$ & 0.074 & 0.091 & 0.115 & 0.642 & 0.521 \\
\hline $\mathrm{SN} \rightarrow \mathrm{PU}$ & 0.154 & 0.176 & 0.102 & 1.510 & 0.131 \\
\hline $\mathrm{SN} \rightarrow \mathrm{PEoU}$ & 0.034 & 0.030 & 0.095 & 0.356 & 0.722 \\
\hline $\mathrm{SN} \rightarrow \mathrm{IM}$ & $0.675^{*}$ & 0.677 & 0.098 & 6.891 & 0.000 \\
\hline
\end{tabular}

\begin{tabular}{lrrrrr}
$\mathrm{IM} \rightarrow$ PU & 0.114 & 0.079 & 0.093 & 1.227 & 0.220 \\
& & & & & \\
$\mathrm{IM} \rightarrow$ PEoU & $\mathbf{0 . 4 0 5 *}$ & 0.378 & 0.108 & 3.764 & 0.000 \\
$\mathrm{JR} \rightarrow$ PU & 0.275 & 0.298 & 0.188 & 1.463 & 0.144 \\
$\mathrm{JR} \rightarrow$ PEoU & 0.244 & 0.278 & 0.140 & 1.735 & 0.083 \\
$\mathrm{OQ} \rightarrow$ PU & 0.095 & 0.039 & 0.101 & 0.936 & 0.349 \\
$\mathrm{OQ} \rightarrow$ PEoU & 0.043 & 0.025 & 0.115 & 0.373 & 0.710 \\
$\mathrm{RD} \rightarrow$ PU & 0.115 & 0.102 & 0.092 & 1.258 & 0.209 \\
RD $\rightarrow$ PEoU & $\mathbf{0 . 2 9 5}^{*}$ & 0.304 & 0.127 & 2.317 & 0.021 \\
\hline
\end{tabular}

Statically significant values are marked $(\mathrm{P}<0.01)$.

*Significant at a significance level of $5 \%$.

\subsection{Discussion}

The TAM in Figure 3 is used to examine the acceptance of the use of the developed intelligent cost estimation model in practice. With the aid of this analysis, a neutral BI can first be determined based on the mean values of the items in Table 2. Since a score of four represents a neutral attitude and only a score of six or higher indicates agreement with a statement, the mean scores of 4.380 and 4.320 can be interpreted as

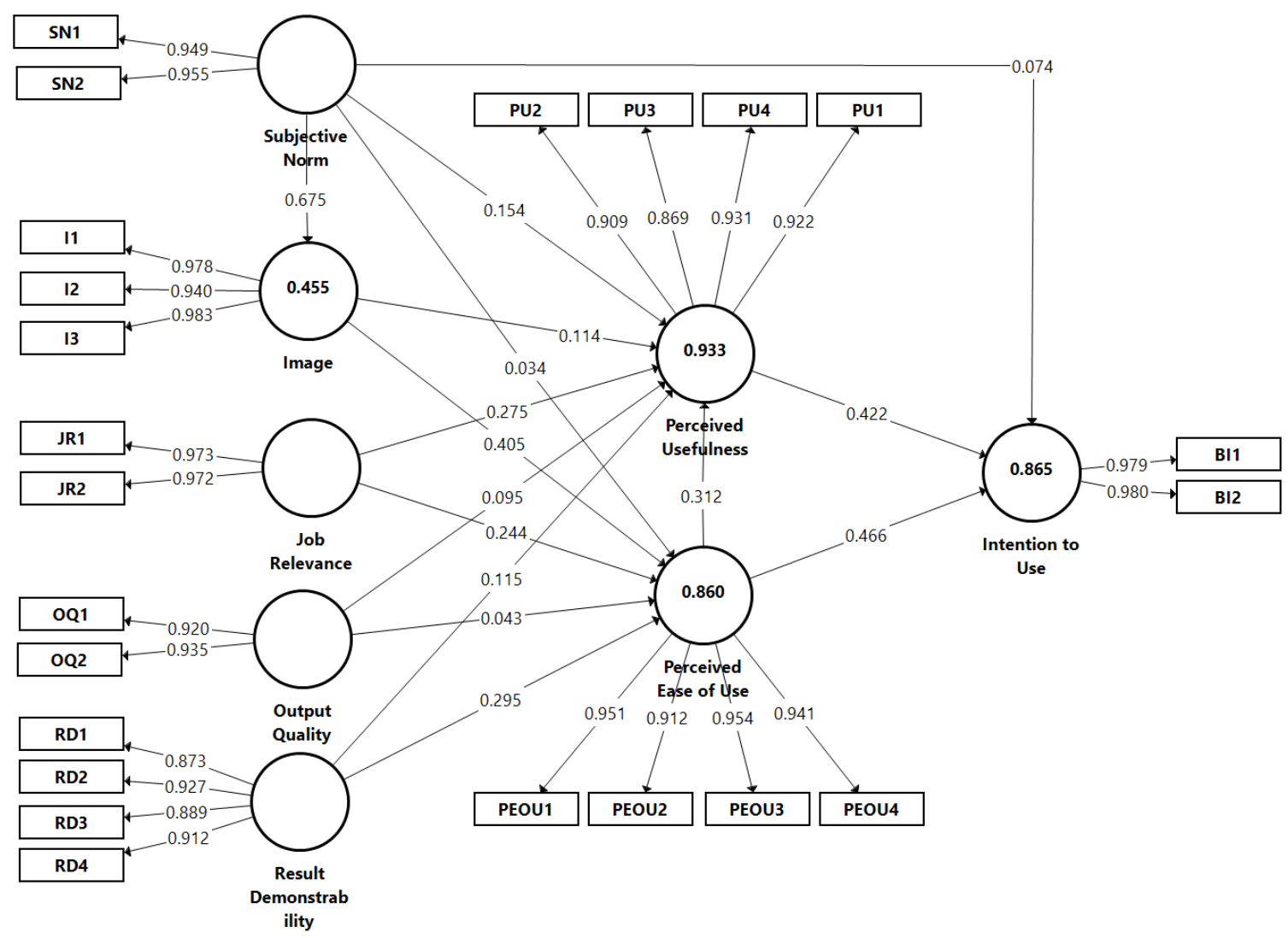

Figure 4. Representation of the structural model with external loadings, path coefficients, and $\mathrm{R} 2$ of the latent constructors. 
a neutral intention to use. Since, as previously mentioned, the establishment of new technologies is influenced by a high level of user acceptance, in this respect the determined user intention of the intelligent cost estimation system is too low and requires more detailed consideration. When comparing the mean values between the PU and the PEoU in Table 2, it can be seen that the PU is higher than the PEoU. Here, the PU of the intelligent cost estimation model is agreed with and recognized on average, whereas the PEoU tends to be disagreed with and rejected on average. If the influence of the two constructs on the BI is also considered in this context, it becomes apparent that both have a significant influence on the BI.

With the help of the analysis of the SEM, the basic assumption of [20] that the PEoU and PU have a significant influence on the BI can be confirmed. In this context, it can also be seen that the IM and the RD have a significant influence on the PEoU. Thereby, the $\mathrm{IM}$ is also significantly influenced by $\mathrm{SN}$. The influence of the derived external variables on the constructs of the basic TAM according to [20] is revealed by the results of the hypothesis tests presented in Table 6 as well as by the results of the TAM presented in Figure 5.

Based on the results of the hypothesis tests in Table 6, the high influence of the PU and PEoU on the BI becomes clear. Due to this fact, to increase the acceptance of the intelligent cost estimation model, an improvement of these two perceptions is of great importance. Since PEoU is rated lower than PU on average, for increasing the acceptance PEoU in particular should be increased, and adjustments should be made to improve it. In this respect, PEoU is mainly influenced by IM and RD, so further developments in these directions in particular may be necessary.

Table 6. Results of the hypothesis tests of the TAM

\begin{tabular}{lll}
\hline $\begin{array}{l}\text { Relation- } \\
\text { ship }\end{array}$ & Hypothesis & Result \\
\hline PU $\rightarrow$ BI & $\begin{array}{l}\text { H1: The PU has a } \\
\text { positive influence on } \\
\text { the BI of the intelligent } \\
\text { cost estimation system. }\end{array}$ & Confirmed \\
PEoU $\rightarrow$ BI & $\begin{array}{l}\text { H2: The PEoU has a } \\
\text { positive influence on } \\
\text { the BI of the intelligent } \\
\text { cost estimation system. }\end{array}$ & Confirmed \\
PEoU $\rightarrow$ PU & $\begin{array}{l}\text { H3: The PEoU has a } \\
\text { positive influence on } \\
\text { the PU of the }\end{array}$ & Not \\
& $\begin{array}{l}\text { intelligent cost } \\
\text { estimation system. }\end{array}$ & \\
& &
\end{tabular}

\begin{tabular}{|c|c|c|}
\hline $\mathrm{SN} \rightarrow \mathrm{BI}$ & $\begin{array}{l}\text { H4: SN has a positive } \\
\text { influence on BI of the } \\
\text { intelligent cost } \\
\text { estimation system. }\end{array}$ & Confirmed \\
\hline $\mathrm{SN} \rightarrow \mathrm{PU}$ & $\begin{array}{l}\text { H5: SN has a positive } \\
\text { influence on PU of the } \\
\text { intelligent cost } \\
\text { estimation system. }\end{array}$ & $\begin{array}{l}\text { Not } \\
\text { confirmed }\end{array}$ \\
\hline $\mathrm{SN} \rightarrow \mathrm{PEoU}$ & $\begin{array}{l}\text { H6: SN has a positive } \\
\text { influence on PEoU of } \\
\text { the intelligent cost } \\
\text { estimation system. }\end{array}$ & Confirmed \\
\hline $\mathrm{SN} \rightarrow \mathrm{IM}$ & $\begin{array}{l}\text { H7: SN has a positive } \\
\text { influence on IM of the } \\
\text { intelligent cost } \\
\text { estimation system. }\end{array}$ & $\begin{array}{l}\text { Not } \\
\text { confirmed }\end{array}$ \\
\hline $\mathrm{IM} \rightarrow \mathrm{PU}$ & $\begin{array}{l}\text { H8: IM has a positive } \\
\text { influence on PU of the } \\
\text { intelligent cost } \\
\text { estimation system. }\end{array}$ & Confirmed \\
\hline $\mathrm{IM} \rightarrow \mathrm{PEoU}$ & $\begin{array}{l}\text { H9: IM has a positive } \\
\text { influence on PEoU of } \\
\text { the intelligent cost } \\
\text { estimation system. }\end{array}$ & $\begin{array}{l}\text { Not } \\
\text { confirmed }\end{array}$ \\
\hline $\mathrm{JR} \rightarrow \mathrm{PU}$ & $\begin{array}{l}\text { H10: JR has a positive } \\
\text { influence on PU of the } \\
\text { intelligent cost } \\
\text { estimation system. }\end{array}$ & Confirmed \\
\hline $\mathrm{JR} \rightarrow \mathrm{PEoU}$ & $\begin{array}{l}\text { H11: JR has a positive } \\
\text { influence on PEoU of } \\
\text { the intelligent cost } \\
\text { estimation system. }\end{array}$ & Confirmed \\
\hline $\mathrm{OQ} \rightarrow \mathrm{PU}$ & $\begin{array}{l}\text { H12: OQ has a } \\
\text { positive influence on } \\
\text { PU of the intelligent } \\
\text { cost estimation system. }\end{array}$ & $\begin{array}{l}\text { Not } \\
\text { confirmed }\end{array}$ \\
\hline $\mathrm{OQ} \rightarrow \mathrm{PEoU}$ & $\begin{array}{l}\text { H13: OQ has a } \\
\text { positive influence on } \\
\text { PEoU of the intelligent } \\
\text { cost estimation system. }\end{array}$ & Confirmed \\
\hline $\mathrm{RD} \rightarrow \mathrm{PU}$ & $\begin{array}{l}\text { H14: RD has a positive } \\
\text { influence on PU of the } \\
\text { intelligent cost } \\
\text { estimation system. }\end{array}$ & Confirmed \\
\hline $\mathrm{RD} \rightarrow \mathrm{PEoU}$ & $\begin{array}{l}\text { H15: RD has a positive } \\
\text { influence on PEoU of } \\
\text { the intelligent cost } \\
\text { estimation system. }\end{array}$ & $\begin{array}{l}\text { Not } \\
\text { confirmed }\end{array}$ \\
\hline
\end{tabular}

All further hypotheses regarding a significant influence cannot be confirmed within the scope of this work. 


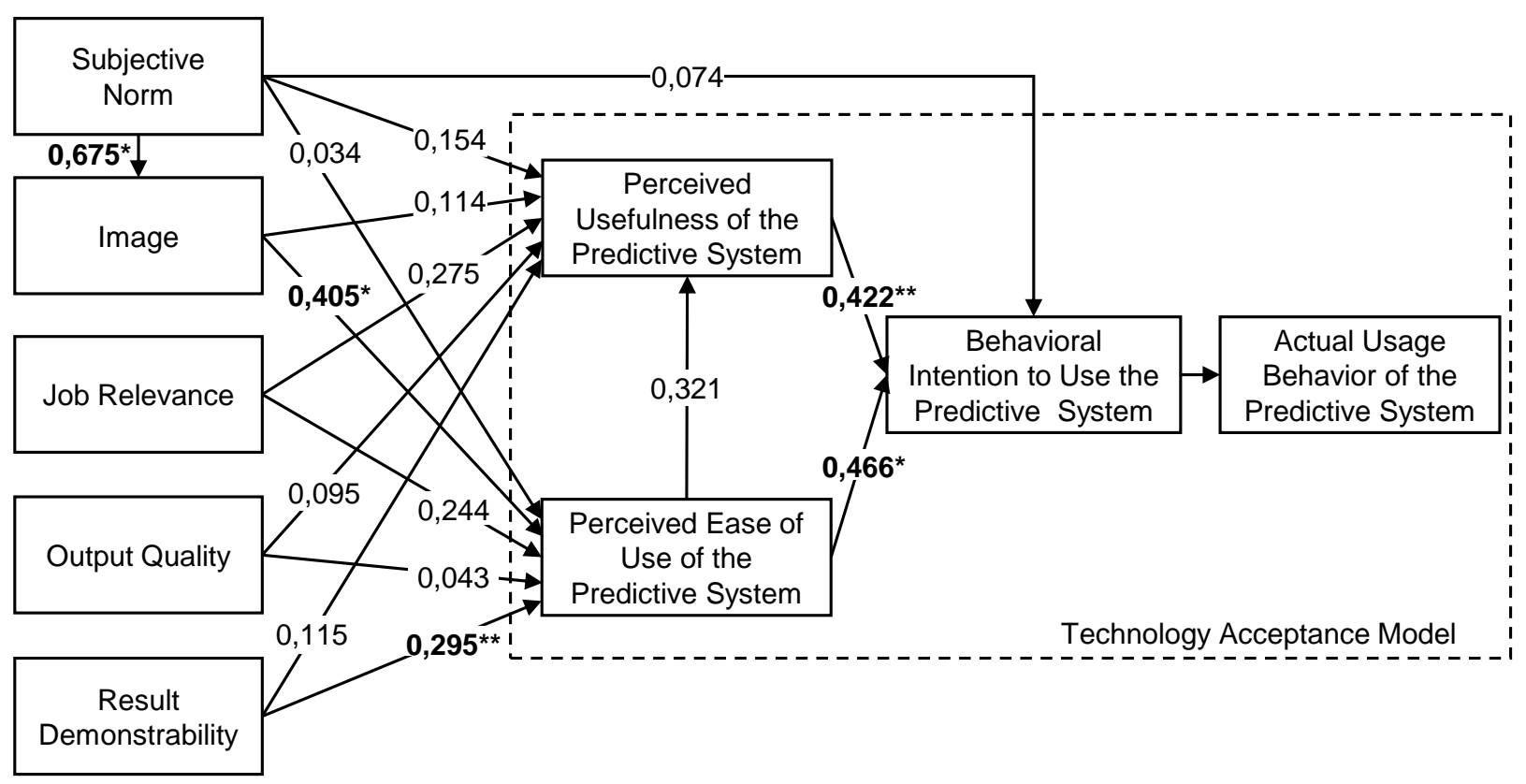

${ }^{*}$ Significant at a significance level of $1 \%$

**Significant at a significance level of $5 \%$.

\section{Figure 5. Results of the TAM for the intelligent cost estimation model}

Due to this, an additional consideration of further external factors could be helpful for identifying the weak points of the acceptance.

To summarize, with the help of the analyzed TAM of this paper, the IM of the intelligent cost estimation system can be explained with an $\mathrm{R}^{2}$ of $45.5 \%$, the PU with an $\mathrm{R}^{2}$ of $93.3 \%$, the PEoU with an $\mathrm{R}^{2}$ of $86.0 \%$ and finally the BI with an $\mathrm{R}^{2}$ of $86.5 \%$. Thus, it can be seen that in order to increase the acceptance of the intelligent cost estimation system, further efforts to improve the PU and especially the PEoU are necessary for a successful adoption of the system in the company.

\section{Research and Management Implications}

The conducted study shows relevant as well as negligible issues for further investigation of the acceptance of intelligent cost estimation models. The significant influence of the perceived usefulness as well as the perceived ease of use following the basic TAM of [20] can be confirmed. In the research of [22] a significant influence on the acceptance of the technology is determined based on the two constructs of job relevance and result quality, which cannot be confirmed however in the given context on the basis of the accomplished questioning. For this reason, in the present use cases more meaningful constructors could be included for more detailed analyses.

Based on the conducted evaluation of the acceptance of the intelligent cost estimation model in the automotive industry, it is evident that this new technology is not fully accepted by the employees. This can mainly be attributed to an insufficiently perceived usefulness and especially to a too low usability. However, since these two constructs have a significant influence on the acceptance and ultimately the adoption of the intelligent cost estimation system, there is a need for further research and action in this regard. In doing so, the background of this result should be analyzed in more detail and the system should be further developed accordingly to promote user acceptance and increase the use of the system in corporate practice.

To prepare the system for use in practice, according to the findings, the subjective norm, the image, and the visibility of the results should be increased in particular to achieve a positive influence on the perceived ease of use.

Data scientists and developers of intelligent cost estimation systems should focus on

- Understandability (making intelligent decision support systems understandable without having to explain its internal structure or algorithms to the end user), 
- Comprehensibility (learning algorithms should be able to report the learned knowledge in a way that is understandable to humans),

- Causality (make the causes of an observed fact understandable through a linguistic presentation of its logical and cause-effect relationships).

- Transparency (create models which are understandable for a human by nature)

In addition, managers could contribute to the userfriendliness by investing in the development of a more intuitive user interface of an estimation model, since according to the empirical study interacting with the system requires expert knowledge and lacks a simple and intuitive operation in practice.

\section{Conclusion}

The TAM analysis of this study exhibits a suboptimal acceptance of the intelligent cost estimation in practice. The theoretical starting point of this study of the acceptance of the intelligent cost estimation model is the TAM according to [22], which has been validated in the literature in different contexts and proved to be a powerful model for studying technology acceptance. In this work, the relationships between eight fundamental constructs for intelligent systems are analyzed. In doing so, the original TAM according to [20] is extended by five external factors related to subjective norm, image, work relevance, visibility of results, and quality of results. A total of 15 hypotheses are analyzed. As a result, based on an online survey in the given context, five hypotheses can be confirmed, and ten hypotheses are rejected. With the help of the applied TAM, the perceived usefulness can be explained with an $\mathrm{R}^{2}$ of $93.3 \%$, the perceived ease of use with an $\mathrm{R}^{2}$ of $86.0 \%$ and finally the intention of the employees to use the system with an $\mathrm{R}^{2}$ of $86.5 \%$. This confirms that the TAM can be used and enhanced for further analysis. In addition, it becomes apparent that in order to increase the acceptance of the intelligent cost estimation system, improvements in terms of perceived usefulness and user-friendliness are generally to be strived for. In this context, further improvements of the system are necessary, predominantly to increase the userfriendliness since the usefulness is basically well perceived.

\section{References}

[1] K. Schütz, M. Kässer, C. Blome and K. Foerstl, "How to achieve cost savings and strategic performance in purchasing simultaneously: A knowledge-based view", Journal of Purchasing and Supply Management, 26(2), 2020, pp. 1-10.
[2] A. Layer, E.T. Brinke, F.V. Houten, H. Kals. And S. Haasis, S., "'Recent and future trends in cost estimation", International journal of computer integrated manufacturing, 15(6), 2002, pp. 499-510.

[3] McKinsey. "What should it cost?",2017. Accessed 15 June 2021. https://www.mckinsey.com/businessfunctions/operations/our-insights/what-should-it-cost

[4] L. Qian and D. Ben-Arieh, D., "Parametric cost estimation based on activity-based costing: A case study for design and development of rotational parts", International Journal of Production Economics, 113(2), 2008, pp.805-818.

[5] H.S. Wang, "Application of BPN with feature-based models on cost estimation of plastic injection products", Computers \& Industrial Engineering, 53(1), 2007, pp. 79-94.

[6] B. Verlinden, J.R. Duflou, P. Collin and D. Cattrysse, "Cost estimation for sheet metal parts using multiple regression and artificial neural networks: A case study", International Journal of Production Economics, 111(2), 2008, pp. 484-492.

[7] S. Deng and T.H. Yeh, "Using least squares support vector machines for the airframe structures manufacturing cost estimation", International Journal of Production Economics, 131(2), 2011, pp.701-708.

[8] J. Bode, "Neural networks for cost estimation," Cost engineering, 40(1), 1998, p.25.

[9] J. Bode, "Neural networks for cost estimation: simulations and pilot application", International Journal of Production Research, 38(6), 2000, pp. 12311254.

[10] S. Cavalieri, P. Maccarrone and R. Pinto, "Parametric vs. neural network models for the estimation of production costs: A case study in the automotive industry", International Journal of Production Economics, 91(2), 2004, pp.165-177.

[11] P.H. Chou, P.H. Li, K.K. Chen and M.J. Wu, "Integrating web mining and neural network for personalized e-commerce automatic service", Expert Systems with applications, 37(4), 2010, pp. 2898-2910.

[12] A. B. Arrieta, N. Díaz-Rodríguez, J. Del Ser, A. Bennetot, S. Tabik, A. Barbado, ... and F. Herrera, "Explainable Artificial Intelligence (XAI): Concepts, taxonomies, opportunities and challenges toward responsible AI", Information Fusion, 58, 2020, pp. 82115.

[13] E.Y. Li, "Artificial neural networks and their business applications", Information \& Management, 27(5),1994, pp. 303-313.

[14] K. Hornik, M. Stinchcombe and H. White, "Multilayer feedforward networks are universal approximators", Neural networks", 2(5), 1989, pp. 359-366.

[15] H. White, "Connectionist nonparametric regression: Multilayer feedforward networks can learn arbitrary mappings", Neural networks, 3(5), 1990, pp. 535-549.

[16] K. Hornik, M. Stinchcombe and H. White, "Multilayer feedforward networks are universal approximators", Neural networks, 2(5), 1989, pp. 359-366.

[17] A. Vellido, P.J. Lisboa and J. Vaughan, "Neural networks in business: a survey of applications (1992- 
1998)", Expert Systems with applications, 17(1), 1999, pp. 51-70.

[18] F. Bodendorf, F., P. Merkl and J. Franke, "Intelligent cost estimation by machine learning in supply management: A structured literature review", Computers \& Industrial Engineering, 2021, p. 107601.

[19] J.S. Edwards, Y. Duan and P.C. Robins, "An analysis of expert systems for business decision making at different levels and in different roles", European Journal of Information Systems, 9(1), 2000, pp. 36-46.

[20] F.D. Davis, "Perceived usefulness, perceived ease of use, and user acceptance of information technology", MIS quarterly,13(3), 1989, pp.319-340.

[21] F. D. Davis, R.P. Bagozzi and P.R. Warshaw, "User acceptance of computer technology: A comparison of two theoretical models", Management science, 35(8), 1998, pp. 982-1003.

[22] V. Venkatesh and F.D. Davis, "A theoretical extension of the technology acceptance model: Four longitudinal field studies", Management science, 46(2), 2000, pp. 186-204.

[23] V. Venkatesh and H. Bala,, "Technology acceptance model 3 and a research agenda on interventions", Decision sciences, 39(2), 2008, pp. 273-315.

[24] V. Venkatesh, M.G. Morris, G.B. Davis and F.D. Davis, "User acceptance of information technology: Toward a unified view", MIS quarterly, 27(3), 2003, pp. 425-478.

[25] C. Changchit, "An investigation into the feasibility of using an internet-based intelligent system to facilitate knowledge transfer", Journal of Computer Information Systems, 43(4), 2003 pp. 91-99.

[26] Y. Liang and S.A. Lee, "Fear of autonomous robots and artificial intelligence: Evidence from national representative data with probability sampling", International Journal of Social Robotics, 9(3), 2017, pp. 379-384.

[27] R.Z. Cabada, M.L.B. Estrada, F.G. Hernández, R. O. Bustillos and C.A. Reyes-García, "An affective and Web 3.0-based learning environment for a programming language", Telematics and Informatics, 35(3), 2018, pp.611-628.

[28] Y. Park, H. Son and C. Kim, "Investigating the determinants of construction professionals' acceptance of web-based training: An extension of the technology acceptance model", Automation in construction, 22, 2012, pp. 377-386.

[29] S.S. Al-Gahtani, S. S., "Empirical investigation of elearning acceptance and assimilation: A structural equation model", Applied Computing and Informatics, 12(1), 2016, pp. 27-50.

[30] J. M. Müller, "Comparing Technology Acceptance for Autonomous Vehicles, Battery Electric Vehicles, and Car Sharing - A Study across Europe, China, and North America", Sustainability, 11(16), 2019, p. 4333.

[31] H. Guner and C. Acarturk, "The use and acceptance of ICT by senior citizens: a comparison of technology acceptance model (TAM) for elderly and young adults", Universal Access in the Information Society, 19(2), 2020, pp. 311-330.

[32] K. Sohn and O. Kwon, "Technology acceptance theories and factors influencing artificial intelligence- based intelligent products", Telematics and Informatics, 47, 2020, p. 101324.

[33] V. Venkatesh, "Determinants of perceived ease of use: Integrating control, intrinsic motivation, and emotion into the technology acceptance model", Information systems research, 11(4), 2000, pp. 342-365.

[34] Y.K.Dwivedi,L. Hughes, E. Ismagilova, G. Aarts, C. Coombs, T. Crick, ... and M.D. Williams, "Artificial Intelligence (AI): Multidisciplinary perspectives on emerging challenges, opportunities, and agenda for research, practice and policy", International Journal of Information Management, 57, 2019, p.101994.

[35] Y. Duan, J.S. Edwards and Y.K. Dwivedi, "Artificial intelligence for decision making in the era of Big Dataevolution, challenges and research agenda", International Journal of Information Management, 48, 2019, pp.63-71.

[36] S. Alsheibani, Y. Cheung and C. Messom, "Artificial Intelligence Adoption: AI-readiness at Firm-Level", Pacific Asia Conference in Information Systems (PACIS), Association for Information Systems, IL USA, 2018, p.37.

[37] J.L. Roldán, M. J. Sánchez-Franco, "Variance-Based Structural Equation Modeling", Research methodologies, innovations, and philosophies, software systems engineering and information systems, Information Science Reference, Hershey, $\mathrm{Pa}, 2012$, pp.193-221.

[38] M. Sarstedt, C.M. Ringle, D. Smith, R. Reams and Jr, J.F. Hair, "Partial least squares structural equation modeling (PLS-SEM): A useful tool for family business researchers", Journal of Family Business Strategy, 5(1), 2014, pp. 105-115.

[39] D. Gefen, D. Straub and M.C. Boudreau, "Structural equation modeling and regression: Guidelines for research practice", Communications of the association for information systems, 4(1), 2000 , p.7.

[40] C.M. Ringle, S. Wende and J.M. Becker, "SmartPLS 3" SmartPLS GmbH, Boenningstedt, Germany. Accessed 15 June 2021. http://www.smartpls.com.

[41] B.G. Tabachnick, L.S. Fidell and J.B. Ullman, "Using multivariate statistics", Pearson, Boston, MA, 5, 2007, pp. 481-498

[42] D. Gefen, and D. Straub, "A practical guide to factorial validity using PLS-Graph: Tutorial and annotated example", Communications of the Association for Information systems, 16(1), 2005, p. 5.

[43] S. Streukens and S. Leroi-Werelds, "Bootstrapping and PLS-SEM: A step-by-step guide to get more out of your bootstrap results", European Management Journal, 34(6), 2016, pp.618-632. 